assessment were included $(\mathrm{n}=452)$ and the last-observation was carried forward in the case of missing data.

Results As shown in the Table 1, functional status improved for subjects on anakinra as their mean HAQ scores decreased by an average of 0.24 . This improvement was both statistically significant, clinically important, and superior to the mean change in subjects receiving placebo. This result was true for each dose of anakinra, as compared to placebo (data not shown).

$\begin{aligned} & \text { Abstract FRI0041 Table } 1 \\
& \text { week 24 }\end{aligned}$
\begin{tabular}{lllll}
\hline & $\begin{array}{l}\text { Placebo } \\
(\mathbf{n}=114)\end{array}$ & $\begin{array}{l}\text { Anakinra } \\
(\mathbf{n}=338)\end{array}$ & Difference & P-value for difference \\
\hline Change in HAQ & -0.03 & -0.24 & -0.21 & 0.0003 \\
\hline
\end{tabular}

Conclusion Subjects receiving anakinra experienced statistically significant improvements in their HAQ scores that exceeded those for subjects on placebo. These improvements were of a magnitude considered clinically important. In subjects with rheumatoid arthritis who are not receiving DMARD therapy, anakinra leads to improvements in functional status.

\section{FRI0042 ANAKINRA IMPROVES FUNCTIONAL STATUS IN PATIENTS WITH RHEUMATOID ARTHRITIS USING METHOTREXATE}

${ }^{1} \mathrm{SB}$ Cohen, ${ }^{2} \mathrm{JM}$ Woolley, ${ }^{2} \mathrm{WW}$ Chan. ${ }^{1}$ Department of Rheumatology, St. Paul Medical Center, Dallas, USA; ${ }^{2}$ Amgen Inc., Thousand Oaks, USA

\subsection{6/annrheumdis-2001.1171}

\section{Background}

Objectives To evaluate the effect of anakinra, with respect to dose response and speed of effect, on the functional status of subjects with rheumatoid arthritis (RA) who were using methotrexate.

Methods In a large, multidose, placebo-controlled study of anakinra, 419 patients with active RA were randomised to receive, in addition to Methotrexate (MTX), either. 04 to $2.0 \mathrm{mg} / \mathrm{kg}$ of anakinra (daily SC injection) or placebo. Functional status was evaluated at baseline and after 4, 8, 12, 16, 20, and 24 weeks of therapy using the Health Assessment Questionnaire (HAQ). Comparisons between MTX alone and anakinra + MTX were analysed using change scores from baseline.

Results Patients receiving higher doses of anakinra experienced rapid and sizeable improvements in their HAQ scores. In percentage terms, HAQ scores improved more than 35 percent over baseline for the two highest doses (data not shown). These improvements occurred rapidly, were related to dose $(\mathrm{p}=$ 0.0014 ), and by week 4 the two highest doses were statistically significantly superior to placebo.

Abstract FRI0042 Table 1 Mean change in HAQ from baseline by dose of anakinra (+MTX) over time

\begin{tabular}{|c|c|c|c|c|c|c|}
\hline & $\begin{array}{l}0 \mathrm{mg} / \\
\mathrm{kg}\end{array}$ & $\begin{array}{l}0.04 \mathrm{mg} / \\
\mathrm{kg}\end{array}$ & $\begin{array}{l}0.10 \mathrm{mg} / \\
\mathrm{kg}\end{array}$ & $\begin{array}{l}0.40 \mathrm{mg} / \\
\mathrm{kg}\end{array}$ & $\begin{array}{l}1.00 \mathrm{mg} / \\
\mathrm{kg}\end{array}$ & $\begin{array}{l}2.00 \mathrm{mg} / \\
\mathrm{kg}\end{array}$ \\
\hline Week 4 & -.10 & -.20 & -.20 & -.19 & $-.26^{*}$ & $-.25^{*}$ \\
\hline Week 8 & -.15 & -.22 & -.21 & -.22 & $-.32^{*}$ & $-.36^{* *}$ \\
\hline Week & -.16 & -.25 & -.20 & -.21 & $-.35^{*}$ & $-.39^{* *}$ \\
\hline
\end{tabular}

\begin{tabular}{lcccccc} 
Week & -.22 & -.22 & -.22 & -.19 & -.32 & $-.45^{*}$ \\
16 & & & & & & \\
Week & -.17 & -.24 & -.30 & -.23 & $-.37^{*}$ & $-.50^{* *}$ \\
20 & & & & & & \\
Week & -.15 & -.25 & -.33 & -.24 & $-.37^{*}$ & $-.51^{* *}$ \\
24 & & & & & \\
\hline${ }^{*} \mathrm{p}<0.05,{ }^{* *} \mathrm{p}<0.01$ for comparison with placebo.
\end{tabular}

Conclusion In patients with active disease despite methotrexate therapy, the addition of anakinra led to rapid and clinically important improvements in functional status. These improvements were related to dose. Anakinra improves functional status in subjects with rheumatoid arthritis.

\section{FRI0043 COMBINATION THERAPY WITH METHOTREXATE AND INFLIXIMAB AS TREATMENT OF REFRACTORY CHRONIC POLYARTHRITIS: OUR EXPERIENCE}

M Covelli, C Scioscia, M Compagno, F lannone, V Grattagliano, G Lapadula. Rheumatology Unit, DIMIMP - Policlinico, Bari, Italy

10.1136/annrheumdis-2001.1172

Background A number of studies show that neutralisation of tumour necrosis factor alpha (TNF-alpha), by using chimeric monoclonal anti-TNF alpha antibody (infliximab) for at least three months, improves the clinical outcome of rheumatoid arthritis. A combination therapy with a standard weekly dose of Methotrexate have been recommended to prevent the activation of autoimmune processes stimulated by the administration of infliximab.

Objectives To evaluate the efficacy and safety of infliximab, when combined with methotrexate, in patients affected by chronic polyarthritis, refractory to other DMARDs.

Methods An open study, including 30 patients affected by different kinds of chronic polyarthritis, is running. Methotrexate (5$15 \mathrm{mg} /$ week) and infliximab (3 mg/kg intravenously at weeks 0 , 2 , 6, and then every 8th week) are administered to all the patients. Clinical evaluation (VAS for pain, VAS as a global assessment by patient and physician, swollen and painful joint count, HAQ score, morning stiffness) and laboratory tests (ESR and CRP), are simultaneously assessed.

Results A marked improvement in clinical symptoms and signs and a reduction of ESR and CRP were seen after the first administration of infliximab. Morning stiffness, swollen and tender joints counts were remarkably reduced and HAQ score significantly improved. One patient experienced allergic reaction at the third infliximab infusion. A cutaneous capillaritis was observed in one patient. Only one patient did not respond to the therapy.

\begin{tabular}{|c|c|c|c|c|c|c|c|c|}
\hline & $\begin{array}{l}\text { ESR } \\
1 \mathrm{st} \mathrm{h} \\
(\mathrm{mm})\end{array}$ & $\begin{array}{l}\text { CRP } \\
(\mathrm{mg} / \\
\mathrm{dl})\end{array}$ & $\begin{array}{l}\text { Morning } \\
\text { stiffness } \\
\text { (minutes) }\end{array}$ & $\begin{array}{l}\text { VAS } \\
\text { pain }\end{array}$ & $\begin{array}{l}\text { HAQ } \\
\text { score }\end{array}$ & $\begin{array}{l}\text { Tender } \\
\text { joints }\end{array}$ & $\begin{array}{l}\text { Swollen } \\
\text { joints }\end{array}$ & $\begin{array}{l}\text { Patient's } \\
\text { global } \\
\text { assessment }\end{array}$ \\
\hline $\begin{array}{l}\text { Time } \\
0\end{array}$ & 31.9 & 5.5 & 82.5 & 62.167 & 1.027 & 22.9 & 15.5 & 72.33 \\
\hline $\begin{array}{l}\text { Week } \\
2\end{array}$ & 18.8 & 1.16 & 5.41 & 32.167 & 0.639 & 8.29 & 2.83 & 33.46 \\
\hline $\begin{array}{l}\text { Week } \\
6\end{array}$ & 17.5 & 1.65 & 5 & 28.5 & 0.47 & 4.74 & 3.39 & 34.26 \\
\hline
\end{tabular}




\begin{tabular}{lllllllll} 
Week & 18.7 & 1.19 & 3.81 & 25.43 & 0.376 & 4.95 & 1.9 & 27.1 \\
$\begin{array}{l}14 \\
\text { Week }\end{array}$ & 20.7 & 0.9 & 6.47 & 22.9 & 0.364 & 4.7 & 1 & 27.9 \\
22 & & & & & & & & \\
$\begin{array}{l}\text { Week } \\
\text { 30 }\end{array}$ & 18.5 & 1.6 & 1.25 & 22.67 & 0.325 & 5.66 & 1.83 & 27.58 \\
\hline Clinical and laboratory data (mean values) after 30 weeks.
\end{tabular}

Conclusion Our data show that, after 30 weeks of treatment, combination therapy with methotrexate and infliximab is a safe and efficient treatment for patients affected by chronic polyarthritis, not responding to other DMARDs. In most patients a remarkable improvement of clinical activity (VAS for pain, VAS as a global assessment by patient and physician, swollen and painful joint count, HAQ score, morning stiffness) and laboratory tests (ESR, CRP) have been observed. The updated data will be presented.

\section{REFERENCES}

1 Elliott MJ, Maini RN, et al. Randomised double-blind comparison of chimeric monoclonal antibody to tumour necrosis factor alpha (CA2) versus placebo in rheumatoid arthritis. Lancet 1994;344(8930):1105-10

2 Kavanaugh A, St Clair EW, et al. Chimeric anti-tumor necrosis factor-alpha monoclonal antibody treatment of patients with rheumatoid arthritis receiving methotrexate therapy. J Rheumatol. 2000:27(4):841-50

3 Lipsky PE, van der Heijde DM, et al. Infliximab and Methotrexate in the Treatment of Rheumatoid Arthritis. N Engl J Med. 2000;343(22):1594-602

\section{FRI0044 EARLY TREATMENT WITH DMARDS IMPROVES RADIOLOGICAL OUTCOME IN PATIENTS WITH RHEUMATOID ARTHRITIS}

CF Allaart, JW Wieringa, TW Huizinga, FC Breedveld. Rheumatology, Leiden University Medical Center, Leiden, The Netherlands

\subsection{6/annrheumdis-2001.1173}

Background For years, patients with rheumatoid arthritis were treated with DMARDs only if they showed severe disease progression with insufficient relieve with NSAIDs. Anti-malarials were prescribed more often than methotrexate and sulphasalazin. However, since side effects of DMARDs and NSAIDs have been shown to be similar, and because it is apparent that radiological damage occurs early in the course of rheumatoid arthritis, rheumatologists have gradually become more aggressive in the treatment of RA: DMARDs, especially methrotrexate and sulphasalazin, are prescribed earlier and in higher dosages, sometimes also in combinations. Do the patients benefit from this change in attitude?

Objectives

Methods Since 1993 patients with recent onset arthritis are seen and followed up in our Early Arthritis Clinic. In a retrospective study of all patients who were diagnosed in $1994(\mathrm{n}=28)$ and 1998 ( $\mathrm{n}=52$ ) with RA and probable RA ( 1 in 1994, 2 in 1998), we evaluated the erosion progression (Sharp/van der Heijde method) between the time of presentation and 2 years later.

Results in 1994, 28 patients and in 1998, 52 patients were diagnosed with RA or probable RA ( $n=1, n=2$, resp.). At presentation, there were no differences in sex distribution, mean age, duration of symptoms, number of inflamed joints, mean ESR, percentage positive for Rheumatoid Factor-IgG, or Sharp/van der Heijde score. Mean duration after presentation before a DMARD was started in 1994 was 7.9 months, in 1998 1,8 months. After 2 years follow-up, 36\% of patients included in 1994 were still without DMARD-treatment, and of 36\% who started on antimalarials, $60 \%$ were still on those drugs. Of the patients included in 1998, 4\% had received no DMARDs in the next 2 years, and $63 \%$ resp. 13\% received sulphasalazin resp. methotrexate as first drug. Of the $20 \%$ who started on antimalarials, 60\% had discontinued and started another DMARD after on average 6 months. The average progression of the Sharp/van der Heijde score was 36.5 for the patients included in 1994, and 9.5 for those included in 1998.

Conclusion Changes in perception of how to treat RA, inspired by less fear for side effects of DMARDs and awareness of early joint destruction, have resulted in less erosion progression in the patients.

\section{FRI0045 DEVELOPMENT OF AN EVIDENCE-BASED REFERRAL RECOMMENDATION (ERR) FOR THE OPTIMUM DMARD TREATMENT OF PATIENTS WITH EARLY STAGE RHEUMATOID ARTHRITIS (RA)}

${ }^{1} \mathrm{P}$ Emery, ${ }^{2} \mathrm{~F}$ Breedveld, ${ }^{3} \mathrm{M}$ Dougados, ${ }^{4} \mathrm{~J}$ Kalden, ${ }^{5} \mathrm{M}$ Schiff, ${ }^{6} \mathrm{~J}$ Smolen. ${ }^{1}$ Rheumatology and Rehabilitation, University of Leeds School of Medicine, Leeds, UK; ${ }^{2}$ University of Leiden, The Netherlands; ${ }^{3}$ University of Rene Descartes, France; ${ }^{4}$ University of Erlangen-Nuremberg, Germany; ${ }^{5}$ University of Colorado, USA; ${ }^{6}$ University of Vienna and Lainz Hospital, Austria

\subsection{6/annrheumdis-2001.1174}

Background In patients with active rheumatoid arthritis (RA), early diagnosis and initiation of DMARD therapy can substantially improve the long-term outcome of disease, as well as overall quality of life. However, delay in referral to a rheumatologist for an accurate diagnosis of RA is a major obstacle to early treatment initiation. A clinical guideline that facilitates early referral of the patient with active RA, and thus the early initiation of DMARD therapy, is required so that treatment is initiated at the most appropriate time to positively impact on long-term morbidity and mortality.

Objectives To develop an ERR for early RA that would serve as a clinical guide for primary care physicians to identify patients with suspected RA during the early inflammatory stages of the disease.

Methods A literature search targeting early RA, early RA clinics (EACs), DMARD therapy for early RA, prognostic disease progression, early RA clinical trials and quality of life was performed. Published clinical evidence was reviewed and classified into categories I-IV ( $\mathrm{I}=$ meta-analysis of/or randomised control trial; IV = expert opinion) and graded $(\mathrm{A}=$ category $\mathrm{I} ; \mathrm{D}=$ category IV) according to the methodology defined by Shekelle et al. (BMJ 1999;318: 593-6). Key points supported by relevant clinical evidence were developed and critically evaluated. Using an iterative process, participants' views were incorporated into a final draft, resulting in a consensus statement.

Results Clinical evidence (Grade C) derived from EACs, prognostic factors for RA, and the consensus of the authors, resulted in the formation of the ERR, which states that rapid referral to a rheumatologist is necessary in the event of clinical suspicion of RA, which may be supported by the presence of any of the following: more than or equal to 3 swollen joints, metacarpophalangeal/metatarsophalangeal involvement and/or morning stiffness of more than or equal to $30 \mathrm{~min}$. This recommendation is strongly supported by graded clinical evidence that structural damage occurs early in RA (Grade B\&C) and that early DMARD therapy improves the long-term outcome of the disease (Grade A). 